Folgende Sternbedeckungen waren sehr gut zu beobachten, auch ohne Abblendung der schwachen Sichel:

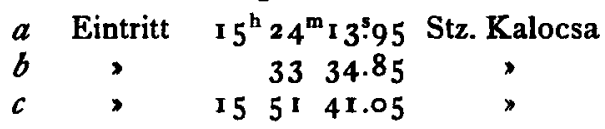

Bemerkungen: $a$ verschwindet plötzlich, vielleicht $0^{\mathbf{s}}, \mathrm{t}$ zu spät beobachtet; $b$ verschwindet allmählich, unsicher ; $c$ gut, vielleicht $0: 3$ zu spät.

Rohe Position der Sterne, Epoche $\mathbf{1 8 5 2 .}$

$\begin{array}{rrrrr} & \alpha & \delta & \text { Gr. } \\ a & 15^{\mathrm{h}} 14^{\mathrm{m}} \mathbf{4 2}^{\mathrm{s}} & -19^{\circ} 16^{\prime} & 8^{\mathrm{m}} \\ b & 145^{2} & 1912 & 9 \\ c & 1515 \mathrm{I2}^{2} & -19 \mathrm{I3} & 8.8\end{array}$

Die beobachteten Sterne wurden nach der Ocularaufnahme mit Hülfe des Chacornac'schen Atlas Nr. 46 identificirt; die Positionen kann ich aber nicht genau geben, da

Kalocsa 1892 Juni 16. ich die Sterne in keinem Cataloge finden konnte. Verwechselungen sind aber ausgeschlossen, wie auch die Pariser Sternkarte erkennen lässt. *)

Die Zeitbestimmung wurde mittelst des Passagerohres während der Finsterniss vom Assistenten ausgefuhrt. Es ergeben nach dem B. J.

$\begin{array}{llr}\gamma \text { Librae } & 6 \text { Fäden } & +26.96 \\ \beta \text { Serp. } & 7 & +26.94 \\ \zeta \text { Urs. min. } & 5 & +26.88\end{array}$

Die Beobachtung der Sternbedeckungen geschah in der Weise, dass ich im Augenblick des Eintrittes mit dem elektrischen Drücker ein Zeichen gab, während der Assistent, vor der Hauptuhr stehend, diesen Zeitpunkt beobachtete und notirte. Die persönliche Gleichung ist unbekannt. Die Höhe des Fernrohres beträgt $109 \mathrm{~m}$ uber dem Adriatischen Meer.

*) Die Sterne sind $a=$ BD. $-19.4091, b=$ BD. $-199^{\circ} 4093, c=$ BD. $-199^{\circ} 4095$.

F. Fényi, s. J.

$K r$.

\title{
Correction der Ephemeride von (306) Unitas in A. N. 3103.
}

Nach zwei Karlsruher Beobachtungen vom 28. und 29. Juli beträgt die Correction der von Herrn Berberich in A. N. 3103 mitgetheilten Ephemeride nur $-6^{\text {s }}$ und $+4^{\circ}$.

Karlsruhe 1892 Juli 30.

Dr. F. Ristenpart.

\section{Benennung der von Dr. M. Wolf entdeckten Planeten (323), (325) und (330).}

Den Planeten ( 323$)$ und (325) hat der Entdecker, Dr. M. Wolf in Heidelberg die Namen $*$ Brucia resp. Heidelbergak zuertheilt. In Bezug auf (330) wünscht der Entdecker, dass ich den Namen vorschlagen solle. Indem ich dieser ehrenden Aufforderung mit Dank nachkomme, wähle ich den Namen sIlmatar*, in der Finnischen Mythologie Tochter der Luft, die Erde und Himmel, Sonne, Mond und Sterne hervorbringt.

Kiel 1892 Juli 10.

A. Krueger.

\section{Notiz betr. die Nummerirung der kleinen Planeten.}

Im Einverständniss mit dem Herausgeber des Berliner Astronomischen Jahrbuches, Prof. Tietjen, wird der unterzeichnete Herausgeber der Astronomischen Nachrichten die neuen Planeten von jetzt an zunächst nur mit einer provisorischen Bezeichnung, 18.. A, B, C, ., nach dem Datum der Anmeldung bei der Centralstelle für Astronomische Telegramme versehen. Die definitive Nummerirung wird der Herausgeber des Berliner Astronomischen Jahrbuchs erst später zu geeigneter Zeit vornehmen und hierbei alle diejenigen Planeten, bei denen ein genügendes Material zur Berechnung der Bahnelemente nicht vorhanden sein sollte, von der Nummerirung ausschliessen.

Kiel 1892 Juli 15.

A. Krueger.

\section{Inhalt:}

Zu Nr. 3105-06. Edwin B. Frost. Observations on the thermal Absorption in the Solar Atmosphere. 129. - Beobachtungen der partiellen Mondfinsterniss 1892 Mai I1. 145. - F. Ristenpart. Correction der Ephemeride von (306) Unitas in A. N. 3 I03. 159. - Benennung der von Dr. M. Wolf entdeckten Planeten (323), (325) und (330). 159. - Notiz betr. die Nummerirung der kleinen Planeten. 159. 